\title{
Analisis Potensi dan Efektivitas Pemungutan Pajak Restoran Terhadap Realisasi Penerimaan Pajak Restoran Di Kecamatan Kuta Selatan
}

\author{
Ni Luh Putu Indah Anggreni' \\ Fakultas Ekonomi dan Bisnis \\ Universitas Udayana, Indonesia \\ Email: indahanggreni85@gmail.com
}

\author{
Maria Mediatrix Ratna Sari ${ }^{2}$ \\ Fakultas Ekonomi dan Bisnis \\ Universitas Udayana, Indonesia
}

\begin{abstract}
ABSTRAK
Tujuan penelitian ini untuk mengetahui berapa besar potensi dan efektivitas pemungutan pajak restoran di Kecamatan Kuta Selatan. Penelitian ini telah dilakukan di berbagai restoran yang terdapat di Kuta Selatan. Jumlah sampel adalah 94 restoran, 14 rumah makan, dan 4 bar, dengan metode probability sampling, khususnya Simple Random Sampling. Pengumpulan data dilakukan melalui observasi non partisipan, survei, dan kuesioner. Teknik analisis dalam penelitian ini adalah deskriptif kuantitatif. Dari hasil analisis menunjukan bahwa potensi pajak restoran di Kecamatan Kuta Selatan tahun 2019 cukup besar bila dibandingkan dengan realisasi dan target pajak restoran. Efektivitas pemungutan pajak restoran di Kecamatan Kuta Selatan tahun 2018 yang menghasilkan sebesar 108 persen dengan kriteria sangat efektif.
\end{abstract}

Kata Kunci: Potensi; Efektivitas; Realisasi Penerimaan.

Analysis of the Potential and Effectiveness of Restaurant Tax Collection Against the Realization of Restaurant Tax Revenue in the District of South Kuta

\section{ABSTRACT}

The purpose of this study was to determine how much the potential and effectiveness of restaurant tax collection in the District of South Kuta. This research has been conducted in various restaurants located in South Kuta. The number of samples is 94 restaurants, 14 restaurants, and 4 bars, with probability sampling methods, especially Simple Random Sampling. Data collection is done through surveys, non-participant observation, and questionnaires. The analysis technique used is quantitative descriptive. The analysis shows that the restaurant tax potential in South Kuta District in 2019 is quite large when compared to the realization and target of restaurant tax. The effectiveness of restaurant tax collection in South Kuta District in 2018 which resulted in 108 percent with very effective criteria.

Keywords: Potency; Effectiveness; Realization of Revenue.

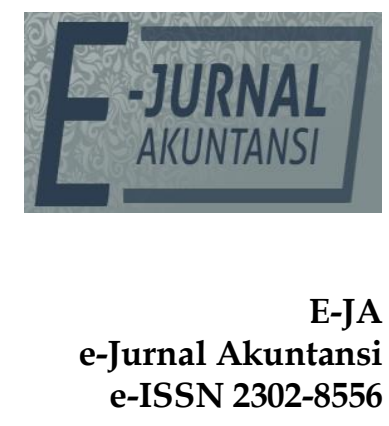

Vol. 30 No. 3

Denpasar, Maret 2020

Hal. 652-661

Artikel Masuk:

1 Desember 2019

Tanggal Diterima: 15 Januari 2020 


\section{PENDAHULUAN}

Dalam usaha menopang eksistensi otonomi daerah, suatu daerah ditantang untuk mempersiapkan strategi perencanaan pembangunan yang akan diambil. Pemerintah Daerah dituntut untuk membiayai kebutuhan rumah tangganya sendiri sehingga dapat memaksimalkan pontensi yang dimiliki (Wirawati \& Putra, 2019). PAD (Pendapatan Asli Daerah) yaitu penerimaan yang diperoleh oleh daerah yang berasal dari sumber yang tersedia dalam wilayahnya sendiri, dipungut sesuai dengan Peraturan Daerah dan Peraturan Perundang-undangan yang berlaku (Mariani, 2018) dan (Febri, 2018). Peningkatan PAD menjadi salah satu fokus baik melalui pemerintahan yang lebih baik atau melalui penciptaan sumber-sumber pendapatan baru, serta melalui stategi lain (Islmet, 2019). Menurut (Yeni \& Galih, 2018) menyatakan bahwa pajak merupakan salah satu penerimaan daerah yang memiliki beberapa sumber dan digunakan untuk membiayai pembangunan. Dalam memajukan daerah dan membiayai pembangunan dapat dilakukan dengan cara mengoptimalkan penerimaan daerah, dimana setiap orang sadar untuk membayar pajak sesuai kewajibannya.

Pajak daerah merupakan komponen yang digunakan untuk membiayai kebutuhan suatu daerah (Irene 2018) dan (Linda, et al., 2019). Disimpulkan bahwa pajak daerah adalah kontribusi wajib pajak daerah terutang oleh orang pribadi atau badan yang bersifat memaksa dengan berdasarkan Undang-undang, dan tidak mendapatkan imbalan secara langsung serta digunakan untuk keperluan daerah (Lumintang \& Tinangon, 2015). Menurut Irene \& Renniwaty, (2018), pajak restoran merupakan salah satu jenis pajak daerah dengan potensi yang semakin berkembang seiring dengan diperhatikannya sektor jasa dan pariwisata dalam kebijakan pembangunan sehingga dapat menunjang berkembangnya bisnis rekreasi atau pariwisata. Pajak restoran adalah salah satu pajak yang dikelola secara mandiri oleh masing-masing pemerintah daerah, dengan demikian pajak restoran merupakan salah satu sumber lokal yang dimanfaatkan untuk membiayai pelaksanaan urusan Pemerintah Daerah (Science, 2019). Jasa yang disediakan oleh restoran termasuk layanan penjualan makanan dan atau minuman yang dikonsumsi oleh pembeli, baik dikonsumsi ditempat pelayanan dan di tempat lain (Lalas \& Prima, 2019). Meningkatnya sektor pariwisata sejalan dengan meningkatnya penerimaan pajak restoran. Menurut Peraturan Daerah Kabupaten Badung Nomor 16 Tahun 2011, restoran adalah fasilitas penyedia makanan dan/atau minuman dengan dipungut bayaran, yang mencakup juga rumah makan, kafetaria, kantin, warung, bar dan sejenisnya termasuk jasan boga/catering.

Potensi merupakan kesanggupan pemerintah dalam membiayai semua penyelenggaraan pemerintah dan pelaksanaan pembangunan guna mencapai tujuan Negara. Potensi pajak restoran dapat diukur berdasarkan data kapasitas, rata-rata harga makanan/minuman, rata-rata pengunjung, dan jumlah hari. Menurut Utami \& Ningsih (2018) menyatakan bahwa efektivitas pajak daerah adalah penilaian kinerja pemungutan pajak daerah yang dilakukan oleh Pemerintah Daerah selama satu tahun anggaran, apakah sudah efektif atau sebaliknya, yang dapat dilihat dari presentase penerimaan pajak daerah yang terealisasi dibandingkan dengan target yang telah ditetapkan. Penelitian 
Linggar, (2016) dan Yuliandari, et al., (2017) mengemukakan bahwa efektivitas menunjukan sampai seberapa jauh tercapainya suatu tujuan ataupun target yang terlebih dahulu ditentukan.

Kabupaten Badung merupakan sebuah kabupaten yang terletak di provinsi Bali. Kabupaten Badung dapat dikategorikan memiliki Pendapatan Asli Daerah (PAD) tertinggi dan potensi terbesar PAD yang bersumber dari pajak hotel dan restoran. Berikut merupakan gambaran penerimaan pajak restoran dan kontribusinya terhadap pajak daerah Kabupaten Badung dari tahun 2014 sampai dengan tahun 2018.

Tabel 1. Penerimaan Pajak Restoran dan Kontribusi terhadap Pajak Daerah Kabupaten Badung Tahun 2014-2018

\begin{tabular}{cccc}
\hline Tahun & $\begin{array}{c}\text { Realisasi Penerimaan } \\
\text { Pajak Restoran (Rp) }\end{array}$ & $\begin{array}{c}\text { Pendapatan Asli Daerah } \\
(\text { PAD) }\end{array}$ & Kontribusi (\%) \\
\hline 2014 & $264.628 .244 .501,50$ & $2.722 .625 .562 .620,69$ & 9,72 \\
2015 & $323.911 .681 .347,84$ & $3.001 .464 .260 .000,00$ & 10,79 \\
2016 & $400.430 .347 .729,69$ & $3.563 .459 .640 .000,00$ & 11,24 \\
2017 & $475.939 .453 .837,24$ & $4.172 .457 .400 .000,00$ & 11,41 \\
2018 & $624.456 .631 .009,54$ & $5.272 .457 .400 .000,00$ & 11,84 \\
\hline
\end{tabular}

Sumber: Badan Pendapatan Daerah Kabupaten Badung, 2019.

Berdasarkan Tabel 1. penerimaan pajak restoran dan kontribusi terhadap Pendapatan Asli Daerah (PAD) dari tahun 2014 sampai tahun 2018 terlihat mengalami peningkatan setiap tahunnya. Ini menunjukan bahwa pajak restoran memiliki kontribusi terhadap penerimaan daerah sebagai sumber pembiayaan pembangunan daerah.

Tabel 2. memberikan gambaran besarnya target pajak restoran yang telah ditentapkan oleh Pemerintah Daerah dibandingkan dengan besarnya realisasi pajak restoran serta proporsi target penerimaan pajak restoran terhadap realisasi pajak restoran dari tahun 2014 sampai dengan tahun 2018.

Tabel 2. Perkembangan Realisasi dan Target Penerimaan Pajak Restoran Kabupaten Badung Tahun 2014-2018.

\begin{tabular}{cccc}
\hline $\begin{array}{c}\text { Tahun } \\
\text { Anggaran }\end{array}$ & $\begin{array}{c}\text { Target Pajak Restoran } \\
(\mathrm{Rp})\end{array}$ & $\begin{array}{c}\text { Realisasi Pajak Restoran } \\
(\mathrm{Rp})\end{array}$ & $\begin{array}{c}\text { Proporsi Target } \\
\text { Terhadap Realisasi } \\
(\%)\end{array}$ \\
\hline 2014 & $204,000,000,000.00$ & $264,628,244,501.50$ & 130 \\
2015 & $277,000,000,000.00$ & $323,911,681,347.84$ & 117 \\
2016 & $336,913,444,429.51$ & $400,430,347,729.69$ & 119 \\
2017 & $451,934,732,795.59$ & $475,939,453,837.24$ & 105 \\
2018 & $579,083,731,320.87$ & $624,456,631,009.54$ & 108 \\
\hline
\end{tabular}

Sumber: Badan Pendapatan Daerah Kabupaten Badung, 2019.

Berdasarkan Tabel 2. dapat diketahui bahwa realisasi penerimaan pajak restoran di Kabupaten Badung dari tahun 2014 sampai dengan tahun 2018 terus mengalami kenaikan. Kemudian realisasi penerimaan pajak restoran tersebut melebihi target pajak restoran yang telah ditetapkan oleh Pemerintah Daerah. Dengan realisasi yang melebihi target, hal ini mengindikasikan bahwa ada potensi yang lebih besar dari realisasi dan ada potensi yang belum tergali secara optimal. Oleh sebab itu, perlu dilakukan kembali analisis potensi terhadap restoran.

Berita Radar Bali (Mustofa, 2019), DPRD Badung mempertanyakan mengenai kinerja Bapenda Badung (Badan Pendapatan Daerah) terkait dengan 
pendapatan yang tidak tercapai. I Putu Alit Yandinata selaku Komisi III DPRD Badung meminta jajaran Bapenda agar membeberkan realisasi dan target pendapatan telah dicapai serta mempertanyakan hambatan yang mengakibatkan melesetnya target pendapatan daerah. Dilihat perkembangan dari tahun 2014 sampai dengan 2018, realisasi target pendapatan selalu tercapai, bahkan dilihat dari proporsi target dan realisasinya melebihi dari 100 persen. Dengan demikian DPRD Badung meminta agar Bapenda untuk berupaya dalam memaksimalkan potensi-potensi yang ada, sehingga dalam rentang waktu yang tersedia di tahun 2019 ini semua potensi-potensi yang ada bisa tercapai atau terpungut secara maksimal.

Tujuan penelitian ini untuk mengetahui besarnya potensi dan efektivitas pemungutan pajak restoran di Kecamatan Kuta Selatan. Penelitian ini dapat memberikan manfaat baik manfaat teoritis maupun manfaat praktis. Manfaat teoritis yaitu memberikan bukti empiris mengenai teori regulasi dan theory of planned behavior serta dikaitkan dengan potensi pajak dan efektivitas pemungutan pajak restoran pada realisasi penerimaan pajak restoran di Kecamatan Kuta Selatan. Manfaat praktis yaitu dapat memberikan memberikan informasi tentang potensi dan efektivitas pemungutan pajak restoran terhadap realisasi penerimaan pajak restoran dalam pelaksanaan pemungutan pajak daerah di Kecamatan Kuta Selatan, serta menjadi dasar acuan bagi pengembangan penelitian selanjutnya.

Teori regulasi menurut Stigler (1971) merupakan aktivitas mengenai peraturan yang menggambarkan persaudaraan antara kekuatan politik dari sekelompok berkepentingan (eksklusif/industri) sebagai sisi permintaan/demand dan legislatif sebagai suplly. Teori ini menjelaskan bahwa dalam akuntansi diperlukan adanya ketentuan atau aturan-aturan yang membutuhkan peran Pemerintah dalam mengatur ketentuan-ketentuan yang dilakukan oleh perusahaan dalam menentukan informasi. Dimana kebutuhan atas standar akuntansi sektor publik terus berkembang akibat kedinamisan regulasi atau ditandai dengan pelaksanaan otonomi daerah tersebut.

Teori ini dikembangkan oleh Azen \& Madden (1986) yang merupakan pengembangan dari Theory of Reasoned Action (Goleman, et al., 2019). Theory of Planned Behovior (TPB) menjelaskan perilaku individu muncul karena adanya niat untuk berperilaku yang ditentukan oleh tiga faktor (Tiraada, 2013) yaitu Behavioral beliefs, Normatif beliefs, dan Control beliefs. Teori ini dikembangkan untuk memprediksi perilaku-perilaku yang sepenuhnya tidak dibawah kendali individu. Teori ini mengenali adanya kemungkinan bahwa banyak perilaku tidak berada dalam kontrol keperilakuan yang dirasakan dan secara penuh.

\section{METODE PENELITIAN}

Penelitian ini menggunakan desin penelitian deskriptif kuantitaif. Penelitian ini dilakukan pada restoran yang ada di Kecamatan Kuta Selatan, dimana Kecamatan Kuta Selatan ini terdiri dari enam Desa/Kelurahan yaitu Pecatu, Ungasan, Kutuh, Benoa, Tanjung Benoa dan Jimbaran. Lokasi penelitian dipilih di Kecamatan Kuta selatan karena memiliki potensi pariwisata yang cukup bagus sehingga dapat meningkatkan jumlah restoran sebagai salah satu 
pendukung sektor pariwisata dan memungkinkan Kecamatan Kuta Selatan memiliki potensi pajak restoran yang cukup besar.

Populasi dalam penelitian ini adalah semua wajib pajak restoran yang ada di Kuta Selatan. Sampel dalam penelitian ini adalah restoran berjumlah 94, rumah makan berjumlah 14, dan bar berjumlah 4. Teknik Pengambilan sampel dalam penelitian ini dengan menggunakan rumus Slovin berdasarkan penelitian dari (Hairol, 2018) yaitu:

$$
n=\frac{\mathrm{N}}{1+\mathrm{N} \cdot \mathrm{e}^{2}}
$$

Keterangan :

$\mathrm{n}=$ ukuran sampel

$\mathrm{N}=$ ukuran populasi (jumlah wajib pajak)

$\mathrm{e}=$ persentase kelonggaran ketidakpastian karena kesalahan pengambilan sampel yang masih dapat ditolerir yaitu 5 persen.

Jumlah populasi berdasarkan data Dinas Pariwisata Kabupaten Badung menyebutkan bahwa jumlah wajib pajak yaitu 123 restoran, 14 rumah makan, dan 4 bar. Berdasarkan perhitungan Slovin, maka sampel restoran berjumlah 94 . Metode penentuan sampel yang digunakan dalam penelitian ini adalah metode probability sampling dengan pemilihan sampel dilakukan dengan cara Simple Random Sampling.

Potensi pajak merupakan kemampuan yang dimiliki pajak restoran untuk menjadi sumber penerimaan bagi suatu daerah, sehingga dapat dikatakan pajak restoran sebagai target penerimaan pajak (Markus, et al., 2018). (Empirical \& Langford, 2016) mendefinisikan potensi pajak sebagai jumlah maksimum penerimaan pajak yang bisa meningkat pada titik tertentu, tergantung pada karakteristik yang berlaku. Potensi pajak sangat menentukan besarnya pajak daerah yang dipungut, oleh karena itu besarnya potensi pajak perlu diketahui dalam menetapkan besarnya target penerimaan pajak pada suatu periode (Rasmini \& Purbasari, 2017). Analisis perhitungan potensi mutlak diperlukan dalam analisis menetapkan target rasional. Dengan potensi yang ada setelah dibandingkan dengan penerimaan untuk masa yang akan datang, maka akan didapatkan besarnya potensi yang terpendam tersebut (Pertiwi, 2013). Perhitungan potensi pajak restoran berdasarkan Peraturan Daerah Khusus Ibu Kota Jakarta Nomor 9 Tahun 1998, digunakan rumus sebagai berikut.

Potensi Pajak $=(\mathrm{M}+\mathrm{P}) \times \mathrm{N} \times 360$ Hari $\times$ Tarif Pajak Restoran

Untuk mencari $\mathrm{N}$ (jumlah rata-rata pengunjung)

$\mathrm{N}=(\Sigma$ Kursi $\times$ AR $\times$ Jam Efektif $)+\Sigma$ Kursi $\times$ AR $\times$ Jam Tidak Efektif......

Jika potensi telah dihitung dan sudah dibandingkan dengan realisasi dan target tetapi potensi masih melebihi target dan realisasi, maka dalam hal ini dalam menghitung kemungkinan target pajak restoran Kecamatan Kuta Selatan agar target yang ditetapkan Pemerintah dapat melebihi atau mendekati dari potensi yang ada dapat menggunakan rumus (Puspita, 2016) sebagai berikut.

Target Pajak Restoran $=$ Potensi Pajak Restoran $x$ Presentase Bobot .....(4)

Efektifitas yaitu tingkat pencapaian tujuan dan sasaran organisasional yang di tetapkan. Efektivitas digunakan untuk mengukur hubungan antara realisasi penerimaan pajak restoran terhadap target pajak restoran yang telah ditetapkan. Jika konsep efektivitas dikaitkan dengan pemungutan penerimaan 
pajak restoran maka efektivitas yang dimaksud adalah seberapa besar realisasi penerimaan pajak restoran dapat mencapai target yang seharusnya dicapai pada periode tertentu (Nio, et al., 2014). Adapun perhitungan efektivitas pemungutan pajak restoran berdasarkan penelitian Setiawati \& Gayatrie (2018) sebagai berikut.

Efektivitas $=\frac{\text { Realisasi Pajak Restoran }}{\text { Target Pajak Restoran }} \times 100 \%$

Tabel 3. Kriteria Efektivitas

\begin{tabular}{ccc}
\hline No. & Presentase Efektivitas & Keterangan \\
\hline 1 & $>100 \%$ & Sangat Efektif \\
2 & $90 \%-100 \%$ & Efektif \\
3 & $80 \%-90 \%$ & Cukup Efektif \\
4 & $60 \%-80 \%$ & Kurang Efektif \\
5 & $<60 \%$ & Tidak Efektif \\
\hline
\end{tabular}

Sumber: Mahmudi (2010:143)

Metode yang digunakan dalam penelitian ini yaitu survei, observasi non partisipan dan kuesioner. Sumber data dalam penelitian ini adalah data primer dan data sekunder. Data sekunder diperoleh dari beberapa sumber yaitu Dinas Pendapatan Daerah/Persedahan Agung Kabupaten Badung, Dinas Pariwisata Kabupaten Badung dan mengakses data mengenai tarif harga makanan serta reviu di www.zomato.com dan www.traveloka.com.

\section{HASIL DAN PEMBAHASAN}

Data penelitian diperoleh dari hasil kuesioner yang disebarkan kepada responden. Responden penelitian dalam penelitian ini adalah jumlah wajib pajak restoran Kecamatan Kuta Selatan yang terdaftar di Direktori Kabupaten Badung. Data yang didapat adalah Restoran berjumlah 94, Rumah Makan berjumlah 14, dan Bar berjumlah 4 .

Untuk menghitung potensi pajak restoran yaitu dengan mengalikan harga makanan dan minuman per orang, rata-rata pengunjung, jumlah hari dalam satu tahun dan tarif pajak restoran yaitu sebesar 10 persen. Berikut pada tabel 4 memberikan gambaran mengenai jumlah restoran beserta jumlah kursinya.

Tabel 4. Jumlah Restoran dan Jumlah Kursi Restoran di Kecamatan Kuta Selatan Tahun 2019

\begin{tabular}{cccc}
\hline \multirow{2}{*}{ No } & \multirow{2}{*}{ Jenis Restoran } & \multicolumn{2}{c}{2019} \\
& & Jumlah Restoran & Jumlah Kursi \\
\hline 1 & Restoran & 94 & 3.700 \\
2 & Rumah Makan & 14 & 772 \\
3 & Bar & 4 & 168 \\
& Jumlah & 112 & 4.640 \\
\hline
\end{tabular}

Sumber: Direktori Dinas Pariwisata Kabupaten Badung, 2019.

Setelah mengetahui jumlah restoran dan jumlah kursi di Kecamatan Kuta Selatan, maka dapat dihitung potensi pajak restoran yang sebenarnya yaitu dihitung setelah mengetahui tarif makanan dan minuman per orang, rata-rata pengunjung, jumlah hari dalam satu tahun dan tarif pajak restoran sebesar 10 persen dengan menggunakan perhitungan potensi pajak restoran. Dari hasil perhitungan maka diperoleh potensi pajak restoran di Kecamatan Kuta Selatan 
tahun 2019 sebesar Rp73.821.406.500. Hasil perhitungan tersebut menunjukan bahwa potensi pajak restoran di Kecamatan Kuta Selatan cukup besar bila dibandingkan dengan realisasi dan target pajak restoran Kecamatan Kuta Selatan tahun 2018.

Melihat potensi pajak restoran yang masih belum optimal, dalam menetapkan suatu target pajak restoran seharusnya menetapkan sebesar potensi pajak restoran atau mendekati potensi pajak restoran sehingga target yang ditentukan bisa mencapai potensi atau terealisasikan. Dalam menentukan target yang kemungkinan bisa mencapai potensi atau terealisasikan dapat dilakukan dengan menggunakan 3 (tiga) skenario yaitu pesimis, moderat, dan optimis. Perhitungan untuk mendapatkan kemungkinan target pajak restoran yang dapat terealisasikan yaitu dengan mengalikan potensi pajak restoran di Kecamatan Kuta Selatan dengan persentase bobot, dimana mencari persentase bobot yaitu menggunakan perhitungan dari nilai minimum, netral, dan maksimum dari data akupansi rate (AR) efektif.

Potensi di Kecamatan Kuta Selatan berpotensi meningkatkan penerimaan suatu daerahnya. Dengan demikian Pemerintah Daerah dalam menetapkan target pajak restoran seharusnya dapat mendekati potensi atau sebesar potensi pajak restoran dan dapat dilihat dari jumlah kunjungan wisatawan yang berdatangan setiap tahunnya di Kecamatan Kuta Selatan. Hasil penelitian ini mengkonfirmasi theory planned of behavior khususnya normative beliefs, kecamatan Kuta Selatan sebenarnya memiliki potensi pajak restoran yang cukup besar, namun target yang ditetapkan masih lebih rendah ini mengindikasikan bahwa masih ada potensi pajak restoran yang belum digali. Hal tersebut perlu dilakukan peningkatan perilaku pemungutan pajak restoran dalam menjalankan tugasnya. Pemerintah dapat memberikan sanksi bagi wajib pajak restoran yang melanggar Peraturan Perundang-undangan yang berlaku, hal ini juga didukung dengan teori regulasi.

Efektivitas pemungutan pajak restoran Kecamatan Kuta Selatan Kabupaten Badung dihitung dengan membandingkan antara realisasi penerimaan pajak restoran dengan target pajak restoran yang telah ditetapkan. Jika Tingkat efektivitas yang dicapai dapat mendekati rasio 1 (satu) atau 100 persen maka semakin baik tingkat efektivitas tersebut. Tingkat efektivitas dapat memperlihatkan Pemerintah Daerah dalam merealisasikan pajak restoran yang telah ditargetkan sebelumnya. Dari hasil perhitungan efektivitas pajak restoran di Kecamatan Kuta Selatan tahun 2018 sebesar 108 persen dengan kriteria sangat efektif, karena tingkat presentase efektivitas melebihi 100 persen.

Berdasarkan hasil perhitungan efektivitas pemungutan pajak restoran menunjukan bahwa Pemerintah Daerah telah berhasil dalam mencapai target penerimaan pajak restoran yang telah ditetapkan. Hal ini menunjukan bahwa kemampuan Pemerintah Daerah dalam melakukan pemungutan pajak restoran di Kecamatan Kuta Selatan sudah optimal. Tingkat efektivitas yang sangat efektif, patut dipertahankan dan ditingkatkan lagi dengan cara Dinas Pendapatan Daerah/Persedahan Agung Kabupaten Badung agar lebih giat lagi dalam melakukan pemungutan pajak restoran dan mengevaluasi kembali apakah target yang telah ditetapkan sudah sesuai dengan potensi yang sebenarnya. Hasil penelitian ini mengkonfirmasi theory planned of behavior khususnya control beliefs. Adanya pengawasan terhadap wajib pajak restoran dalam pelaksanaan 
pemungutan pajak, agar tidak ada lagi wajib pajak restoran yang melanggar Peraturan Perundangan-undangan yang berlaku. Perlu juga adanya perilaku dalam pemungutan pajak yaitu dengan adanya niat dalam melakukan pekerjaan dengan baik dan maksimal agar target yang diharapkan bisa terealisasi dengan optimal.

\section{SIMPULAN}

Hasil perhitungan potensi pajak restoran di Kecamatan Kuta Selatan tahun 2019 menunjukan hasil sebesar Rp 73.821.406.500. Potensi pajak restoran di Kecamatan Kuta Selatan cukup besar nilainya bila dibandingkan dengan realisasi dan target pajak restoran Kecamatan Kuta Selatan tahun 2018, maka masih ada potensi yang harus digali secara optimal sehingga dapat meningkatkan penerimaan daerah. Pemerintah Daerah dalam menetapkan target pajak restoran seharusnya sebesar potensi atau mendekati potensi pajak restoran yang telah ditetapkan serta dilihat dari jumlah kunjungan wisatawan setiap tahunnya.

Hasil perhitungan efektivitas pemungutan pajak restoran Kuta Selatan Kabupaten Badung menghasilkan sebesar 108 persen dengan tingkat efektivitas sangat efektif. Ini menunjukan Pemerintah Daerah dapat mencapai target yang ditetapkan dan kemampuan Pemerintah Daerah dalam melaksanakan pemungutan pajak restoran telah optimal.

Potensi dan efektivitas pemungutan pajak restoran memiliki potensi yang cukup tinggi dari realisasi dan target, maka diperlukan peran Pemerintah Daerah agar menggali kembali potensi pajak restoran yang cukup besar ini sehingga penerimaan pajak daerah maupun Pendapatan Asli Daerah (PAD) dapat ditingkatkan lagi. Dalam meningkatkan penerimaan pajak restoran di Kecamatan Kuta Selatan perlu dilakukan adanya sosialisasi kepada masyarakat terutama wajib pajak restoran dan objek pajak restoran. untuk peneliti selanjutnya dapat menambah objek penelitian tidak hanya pada pajak restoran tetapi pajak daerah yang lainnya sehingga dapat mengatahui potensi serta efektivitas terhadap penerimaan daerah.

\section{REFERENSI}

Empirical, A., \& Langford, B. (2016). Tax Revenue Potential and E ff ort. Journal International Growth, 2(3), 1-30.

Febri, U. D. (2018). Analysis of Influencing Factors Regional Original Revenue (Pad) in The Provincial Government of Dki Jakarta. E-Journal Stei, 2(5), 1-6.

Goleman, daniel; boyatzis, Richard; Mckee, A. (2019). Analisis Implementasi Sistem Pengendalian Intern Pengelolaan Pajak dan Kontribusi Pajak Restoran dalam Meningkatkan Potensi PAD Kota Palembang. Journal of Chemical Information and Modeling, 53(9), 1689-1699. https:// doi.org/10.1017/CBO9781107415324.004

Hairol, S. (2018). Potensi Penerimaan Pajak Hotel Dan Restorsn Di Kabupaten Ketapang. Artikel Ilmiah, 2(5), 1-6.

Irene, S., \& Renniwaty, S. (2018). Payment Tax Restaurant Does By Taxpayer at Batam's City. Journal UMRI, 3(5), 24-28.

Islmet, S. (2019). An Implementation of Restaurant Tax Policy to Increase Local Revenues in Gorontalo City. Journal Mimbar, 34(2), 406-413. 
Lalas, S., \& Prima, N. (2019). Supervision of Hotel and Restaurant Tax (PAD) Sumedang District. Journal of Economic Emowerment Strategy (JEES), 02(01), 13-23.

Linda, N. Y., Negina, K. P., Yudha, A. S., \& Rafinda, A. (2019). Service Quality And Tax Sanctions On Taxpayer Compliance In. Journal of Accounting and Strategic Finance, 2(1), 1-13.

Linggar, A. P. \& A. H. (2016). The Analysis of The Effectivitiess and Contribution of Regional Retribution Towards Own-Source Revenue (OSR). Journal Universitas Widya Dharma, 6(3), 249-257.

Lumintang, S. F., \& Tinangon, J. (2015). The Analysis of The Effectivities of Tax Revenues of Restaurants and Entertaiment System Based on Tax Assessment And ITS Contribution to The Own-Source Revenue City Saturn. Journal EMBA, 3(2), 1-13.

Mariani, S. (2018). Analysis of the Effectiveness and Contribution of Tax Revenue Against the Original Parking Area (Pad) Surakarta City Year 2012-2016. Journal of Majoring in Accounting Faculty of Economics, 2(5), 1-4.

Markus, S. S., Herman, K., \& Lambey, R. (2018). Analisis Potensi Dan Efektivitas Penerimaan Pajak Reklame Di Kota Manado. Jurnal Riset Akuntansi Going Concern, 13(2), 273-281.

Mustofa, A. (2019). PAD Badung Tak Capai Target, DPRD Pertanyakan Kinerja Badan Pendapatan. Radar Bali. Retrieved from https:// radarbali.jawapos.com/read/2019/07/07/144971/pad-badungtak-capai-target-dprd-pertanyakan-kinerja-badan-pendapatan

Nio, A. S., Topowijono, \& Achmad, H. (2014). Upaya Peningkatan Pendapatan Asli Daerah (Studi pada Dinas Pendapatan Daerah Kabupaten Kediri). Jurnal EPerpajakan, 1(1), 1-10.

Pertiwi, D. I. (2013). Analisis Potensi Pajak Restoran di kawasan Wisata Anyer Kabupaten Serang. Jurnal Akuntansi E Keuangan, Vol. 9(No. 2).

Puspita, A. F. (2016). Analisis Penetapan Target Penerimaan Pajak Daerah (Studi Pada Dispenda Kota Malang). Jurnal Administrasi Dan Bisnis, 10(1), 25-38. Retrievedfromjadbis.polinema.ac.id/index.php/adbis/article/download/8 $/ 4$

Rasmini, M., \& Purbasari, R. (2017). Analysis of The Potential of Advertisement Tax Revenue Installed on People Crossing Bridge (JPO) in Bandung 20162017. Journal Home, 8(4), 212-224.

Science, E. (2019). Policy Communication Strategy of Restaurant Tax to Increase Bandung's Own-Source Revenue Policy Communication Strategy of Restaurant Tax to Increase Bandung's Own-Source Revenue. 2(5), 1-11. https:// doi.org/10.1088/1755-1315/248/1/012068

Setiawati, G. F., \& Gayatrie, C. R. (2018). Analisis Efektivitas Dan Kontribusi Pajak Restoran Terhadap Pendapatan Asli Daerah (Pad) Kabupaten Semarang Giffiany Fibri Setiawati, Christina Retno Gayatrie. 1(2), 127-136.

Stigler, G. J. (1971). The theory regulation of economic. The Bell Journal of Economics and Management Science, 2(1), 3-21. https:// doi.org/10.2307/3003160 
Tiraada, T. A. . (2013). Kesadaran Perpajakan, Sanksi Perpajakan, Sikap Fiskus Terhadap Kepatuhan WPOP di Kabupaten Minahasa Selatan. Jurnal EMBA, 1(3), 999-1008.

Utami, M., \& Ningsih, E. S. (2018). Analisis Efektivitas Dan Kontribusi Penerimaan Pajak Dan Retribusi Daerah Terhadap Pendapatan Asli Daerah Kabupaten/Kota Di Provinsi Aceh Tahun 2011-2015. Jurnal Ilmiah Mahasiswa Ekonomi Akuntansi (JIMEKA), 3(4), 672-687.

Wirawati, N. G. P., \& Putra, I. N. W. A. (2019). Analysisi of Factors That Influence The Compliance of Tax and Restaurant Taxes in Tabanan Regency of Bali, Indonesia. RJOAS : Russian Journal of Agricultural and Sciences, 2(5), 1-18. https:// doi.org/10.18551/rjoas.2019-02.25

Yeni, P., \& Galih, W. (2018). The Analysis of Potential Restaurant Tax Revenue in Banyuwangi Regency. International Seminar Series on Regional Dynamic, 2(5), 1-11.

Yuliandari, R., Chaidir, T., Mahmudi, H., \& Program, M. (2017). The Analysis of Effectivity and Efficiency of Tax Collection from Hotels and Restaurants in Order to Increase the Original Regional Income (PAD) in Mataram. Journal of Ecconomics and Development Studies, 9(2), 251-256. 